\title{
Basic Examination on Assessing Mechanical Properties of Concrete That Has Suffered Combined Deterioration from Fatigue and Frost Damage
}

\author{
Hiroshi Hayashida \\ Materials Research Team, Cold-Region Maintenance Engineering Research Group, \\ Civil Engineering Research Institute for Cold Region \\ Yasuhiko Sato and Tamon Ueda \\ Division of Engineering and Policy for Sustainable Environment, Graduate School of Hokkaido University
}

\begin{abstract}
An examination including an evaluation of mechanical properties of concrete that had suffered combined deterioration from fatigue and frost damage was done using cylindrical specimens. The order of deterioration and degree of deterioration of the specimens were used as variables. The examination clarified that certain mechanical properties of concrete that had undergone combined deterioration were able to be evaluated by measuring the propagation speed of ultrasonic waves. The decrease in the elastic modulus and the ultrasonic velocity that accompanies the increase in the number of freeze-thaw cycles was smaller in the specimens that experienced fatigue first and then frost damage than in the specimens that experienced frost damage only. The values for mechanical properties (e.g., compressive strength, elastic modulus, and shrinkage strain) of the specimen that experienced frost damage first and then fatigue had already greatly decreased after the application of freezethaw cycles. Therefore, the decrease in the mechanical properties was small even with increases in the number of loading cycles. The decrease in the fatigue life of the specimen in the fatigue test was proportional to the deterioration from the preceding frost damage.
\end{abstract}

\section{INTRODUCTION}

Many of the RC slabs on road bridges in cold and snowy regions, where the weather conditions are severe, often suffer combined deterioration from the fatigue of passing vehicles and from frost damage.

The fatigue resistance of $\mathrm{RC}$ slabs on road bridges that had suffered combined deterioration from fatigue and frost damage was studied by using wheel load running tests, and it was reported that the fatigue life of such slabs was shorter than that of slabs that had suffered fatigue only (Mitamura, Sato, Honda, \& Matsui, 2009). The changes in structural performance and the evaluation of certain mechanical properties of $\mathrm{RC}$ slabs on road bridges that have suffered combined deterioration from fatigue and frost damage have not been sufficiently studied or clarified.

To clarify such changes and properties, we examined the mechanical properties of concrete that had suffered combined deterioration from fatigue and frost damage. The data from our study are necessary for examinations on the influence of combined deterioration from fatigue and frost damage on the structural performance of RC structures.
We also examined a method for assessing the mechanical properties of concrete that has suffered combined deterioration from fatigue and frost damage.

\section{OUTLINE OF THE EXPERIMENT}

\subsection{Specimens}

The specimen was a cylinder of $\varphi 100 \mathrm{~mm} \times 200 \mathrm{~mm}$. The mix proportion of the specimen is shown in Table 1. The cement used was ordinary Portland cement, and the aggregate was crushed stone with a maximum grain size of $20 \mathrm{~mm}$. The experiments described below were done after 60 days of water curing of the cast concrete. The compressive strength of the concrete at 60 days old was $29.6 \mathrm{MPa}$. Three specimens were prepared for each of the variables for the experiments described later.

Table 1. Table of mix proportions.

\begin{tabular}{cccc}
\hline $\begin{array}{c}\text { Unit water } \\
\text { content } \\
\left(\mathbf{k g} / \mathbf{m}^{3}\right)\end{array}$ & $\begin{array}{c}\text { Water- } \\
\text { cement ratio } \\
(\%)\end{array}$ & $\begin{array}{c}\text { Sand-coarse } \\
\text { aggregate ratio } \\
(\%)\end{array}$ & $\begin{array}{c}\text { Air void } \\
\text { ratio } \\
(\%)\end{array}$ \\
\hline 184 & 61 & 47.6 & 2.0 \\
\hline
\end{tabular}


The variables for the experiments were deterioration type and deterioration severity. The specimens were categorized into three series based on deterioration type. Series H specimens had only fatigue deterioration. Series $\mathrm{T}$ specimens had only frost damage. And Series HT and TH specimens had combined deterioration from fatigue and frost damage. The specimens with combined deterioration from fatigue and frost damage were subcategorized into those that underwent fatigue and then frost damage (Series HT), and those that underwent frost damage and then fatigue (Series TH).

Three levels of deterioration were set for fatigue damage, and two levels were set for frost damage. In the combined deterioration category, all possible combinations of fatigue and frost damage levels were used. Table 2 shows the specimen names and the variables in the experiment. The letter $\mathrm{H}$ in a specimen indicates that the specimen underwent fatigue, and the number following the $\mathrm{H}$ is the ratio of loadings imposed to loadings required to reach the fatigue life limit (hereinafter: the ratio).The letter $T$ in a specimen indicates that the specimen underwent frost damage, and the number following the $T$ is the number of freeze-thaw cycles imposed. The greater is either of the numbers, the greater is the deterioration. The control specimen, which was subjected to neither fatigue nor frost damage, is Specimen N.

Table 2. The specimens.

\begin{tabular}{llcc}
\hline Series & Name & Ratio (\%) & $\begin{array}{c}\text { Freeze-thaw } \\
\text { cycles (times) }\end{array}$ \\
\hline $\begin{array}{l}\text { Series H } \\
\text { (fatigue only) }\end{array}$ & H20 & 20 & 0 \\
& H50 & 50 & 0 \\
Series T (freeze- & T12 & 0 & 0 \\
thaw only) & T24 & 0 & 12 \\
\hline & H20T12 & 20 & 24 \\
\hline Series HT (fatigue & H50T12 & 50 & 12 \\
then freeze-thaw) & H20T24 & 20 & 12 \\
& H50T24 & 50 & 12 \\
& H80T24 & 80 & 24 \\
& T12H20 & 20 & 24 \\
\hline & T12H50 & 50 & 12 \\
& T12H80 & 80 & 12 \\
Series TH (freeze- & T24H20 & 20 & 12 \\
thaw then fatigue) & T24H50 & 50 & 24 \\
& $\mathrm{~T} 24 \mathrm{H} 80$ & 80 & 24 \\
\hline Sound & $\mathrm{N}$ & 0 & 24 \\
\hline
\end{tabular}

\subsection{Experiment method}

\subsubsection{Cyclic loading test}

The cyclic loading test was done by using an actuator until the loadings reached a set ratio that is described later. The loading was pulsating sinusoidal loading with a frequency of $5 \mathrm{~Hz}$, and the minimum and maximum stress ratios were set as 8 and $68 \%$, respectively, of the compressive strength at the 60th day. In setting the maximum stress ratio, the highest possible value was selected, i.e., the value that was within the range of values that would not cause the specimen to fail in one loading. The minimum stress ratio was set based on JSTMC 7104, and a value that was close to $10 \%$ of the compressive strength was selected. The experiment variable was the ratio. Three levels of ratio were set. In setting the ratio, the relationship between the number of loading cycles until fatigue failure and the strain was determined. Cyclic loading was done until the maximum strain during the cyclic loading test reached about 20,50 , and $80 \%$ of the number of loading cycles required to reach the fatigue life limit. For Series $\mathrm{TH}$, the relationship between the number of loading cycles until the frost-damaged specimen achieved fatigue failure, the strain was determined, and the ratio of cyclic loading was set.

\subsubsection{Freeze-thaw experiment}

The freeze-thaw experiment was done based on the method specified in JIS A 1148. The experiment variable was the number of freeze-thaw cycles. These were set as 12 and 24 times, so as to achieve a relative dynamic elastic modulus of 60 and $20 \%$, respectively.

\subsection{Measured items}

2.3.1 Ultrasonic propagation velocity

After completing the deterioration procedure, the ultrasonic propagation velocity in the direction of the cylindrical axis (hereinafter: ultrasonic velocity) was measured by using the transmission method. The ultrasonic velocity varies depending on the moisture condition (Hayashida, Taguchi, Endo, \& Kusama, 2008). To have moisture conditions as uniform as possible for all the specimens, the measurement was done in the surface-dry condition. More precisely, measurements of ultrasonic velocity for Series $\mathrm{H}$ and Series TH were done in the surface-dry condition. After the cyclic loading, the specimens were submerged in water for 3 days and then dried to the surface-dry condition. Measurements for Series $\mathrm{T}$ and HT were done after the freeze-thaw procedure was completed. The specimens were taken out of the water tank and dried to the surface-dry condition. The ultrasonic sensor had a diameter of $20 \mathrm{~mm}$, a sampling frequency of $28 \mathrm{kHz}$ and a voltage of $1 \mathrm{kV}$. 


\subsubsection{Compressive strength and elastic modulus}

The compressive strength was measured according to JIS A 1108. Strain was measured using a compressometer at the time of the loads were measured, and the elastic modulus was determined according to JIS A 1149.

\section{EXPERIMENT RESULTS AND DISCUSSION}

\subsection{Examination on the evaluation of mechanical properties using ultrasonic velocity}

\subsubsection{Relationship between ultrasonic velocity} and mechanical properties

The relationship between ultrasonic velocity and compressive strength (Figure 1) and that between ultrasonic velocity and elastic modulus (Figure 2) were examined, and the degree of scattering was found to differ between the two figures. Even so, it is possible to obtain an estimation equation for determining the mechanical properties of concrete for each type of deterioration

\begin{tabular}{|lllll|}
\hline$+\mathrm{H} 20$ & $\times \mathrm{H} 50$ & $\times \mathrm{H} 80$ & $-\mathrm{T} 12$ & $-\mathrm{T} 24$ \\
口 $20 \mathrm{~T} 12$ & $\square \mathrm{H} 50 \mathrm{~T} 12$ & $\bullet \mathrm{H} 80 \mathrm{~T} 12$ & $\circ \mathrm{H} 20 \mathrm{~T} 24$ & $\bullet \mathrm{H} 50 \mathrm{~T} 24$ \\
$\bullet \mathrm{H} 80 \mathrm{~T} 24$ & $\Delta \mathrm{T} 12 \mathrm{H} 20$ & $\Delta \mathrm{T} 12 \mathrm{H} 50$ & $\Delta \mathrm{T} 12 \mathrm{H} 80$ & $\circ \mathrm{T} 24 \mathrm{H} 20$ \\
$\bullet \mathrm{T} 24 \mathrm{H} 50$ & $\bullet \mathrm{T} 24 \mathrm{H} 80$ & $\star \mathrm{N}$ & & \\
\hline
\end{tabular}

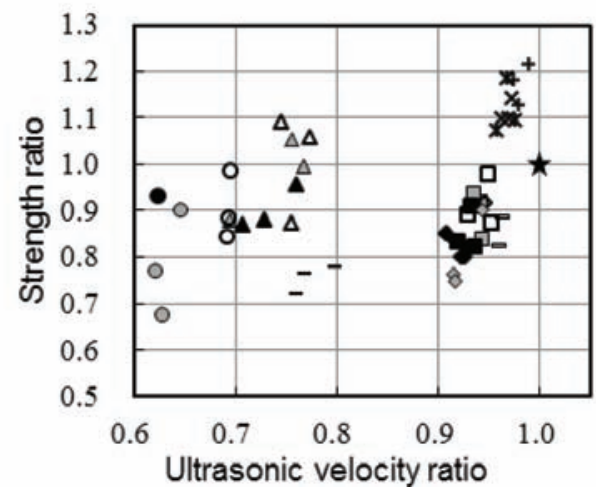

Figure 1. Relationship between ultrasonic velocity and compressive strength.

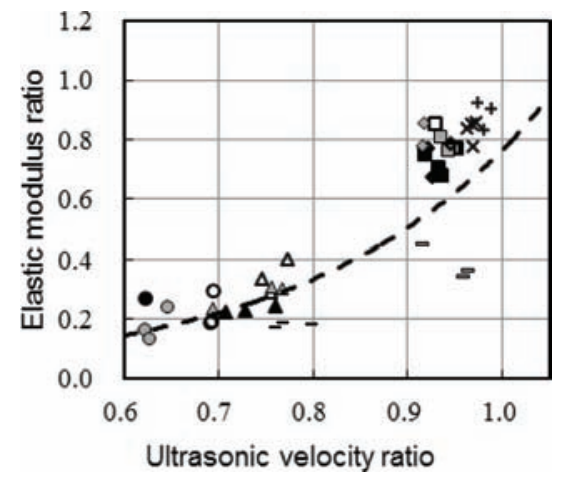

Figure 2. Relationship between ultrasonic velocity and elastic modulus. by using ultrasonic velocity, because a certain level of correlation is found in the relationship between ultrasonic velocity and the mechanical properties of concrete for each type of deterioration. However, the relationship between the ultrasonic velocity and the mechanical properties of concrete for each type of deterioration distribute in a dispersed manner, so obtaining a single estimation equation is difficult.

\subsubsection{Relationship between compressive strength and elastic modulus}

In the case of sound concrete that has not undergone deterioration, there is a correlation between the compressive strength and the elastic modulus. An estimation equation (Equation 1) that uses the compressive strength is shown in the Standard Specifications for Concrete Structures of the Japan Society of Civil Engineering (2012).

$$
E_{c}=\left(2.2+\frac{f_{c}^{\prime}-18}{20}\right) \times 10^{4}
$$

where $E_{c}\left(\mathrm{~N} / \mathrm{mm}^{2}\right)$ : elastic modulus and $f_{c}^{\prime}\left(\mathrm{N} / \mathrm{mm}^{2}\right)$ : compressive strength.

The relationship between the compressive strength and elastic modulus of the concrete that had suffered combined deterioration from fatigue and frost damage was compared to that of the sound concrete that had not suffered any deterioration. Figure 3 shows the relationship between the compressive strength and the elastic modulus of the concrete that had suffered combined deterioration from fatigue and frost damage. An existing estimation equation for sound concrete (hereinafter: "the estimation equation") is shown in the same figure.

As shown in Figure 3, all the experiment series differ from the existing estimation equation; however, a tendency of data dispersion centred around a certain region was found in each series, even though there are differences in the degree of data dispersion.

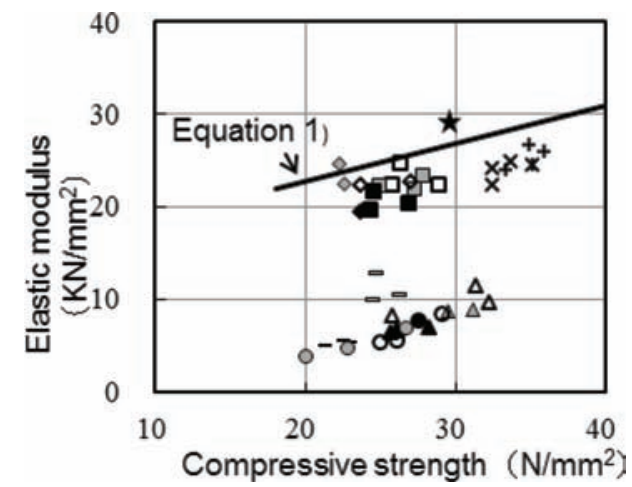

Figure 3. Relationship between compressive strength and elastic modulus. 
When the data distributions are examined individually, we find that the data distribution of Series $\mathrm{H}$ is roughly parallel to that of the estimation equation. The elastic modulus for a given compressive strength is lower for Series $\mathrm{H}$ than the equivalent value from the estimation equation; however, the difference is not very great.

The data distribution for Series $T$ has a steeper slope than that for the estimation equation. The steep slope was created because the decrease in the elastic modulus was greater than the decrease in compressive strength caused by the freeze-thaw action, which was also reported in a previous study (Takashiba, Sakai, \& Kumagai, 1998).

The data point distribution for Series HT shows a similar tendency to that for Series $\mathrm{H}$. The data points distribute below those of the estimation equation and are roughly parallel to the points from the estimation equation. The degree of decrease in elastic modulus is not very large, either. The compressive strength, however, distributes in the region to the left of that for the estimation equation. The compressive strength of Series HT is much lower than that for the estimation equation.

For Series TH, as for Series $\mathrm{H}$ and Series HT, the data tend to distribute roughly parallel to those for the estimation equation; however, the data are distributed in a range that is lower than for any other type of deterioration. At a given compressive strength, the degree of decrease in the elastic modulus for Series $\mathrm{TH}$ is very great compared to that for the estimation equation for a sound specimen.

\subsubsection{Examination on the evaluation of mechanical properties using ultrasonic velocity of concrete that has undergone combined deterioration}

In the case of deterioration from a single cause, as described above, a certain level of correlation is found for each type of cause and the resulting deterioration. It may be possible to evaluate the mechanical properties of concrete that has suffered each type of deterioration by using an estimation equation for each deterioration type.

In the case of combined deterioration, when the order of deterioration is known, as in the current experiment, the mechanical properties of the concrete can be evaluated by using the estimation equation for each type of deterioration. However, in actual structures, fatigue and freeze-thaw damage occur alternately or simultaneously. In using ultrasonic velocity to evaluate the mechanical properties of concrete that has suffered combined deterioration, it is necessary to obtain a single estimation equation.

Examination was done in order to obtain a single equation from the correlation between ultrasonic velocity and elastic modulus, which is higher than that between compressive strength and elastic modulus (Figure 2). The estimation equation for the elastic modulus of the concrete that had suffered combined deterioration was determined as the dotted line in Figure 2. Series HT was excluded from the examination for obtaining a single equation, for the following reason. The strain change from freeze-thaw in Series HT was within the range of strain change from cyclic loading, and the elastic modulus of Series HT did not decrease very much compared with that decrease for Series T. The details are discussed in Section 3.2.2. It was assumed that the elastic modulus of Series HT was close to that of Series TH, whose elastic modulus is even smaller than that of Series HT, because fatigue and freeze-thaw damage act on the concrete simultaneously in actual cases.

Next, estimation of the compressive strength of concrete that had suffered from combined deterioration was examined. Based on the fact that the elastic modulus was able to be estimated from ultrasonic velocity, a method that used the relationship between compressive strength and elastic modulus (Figure 3 ) can be used for estimating compressive strength. The relationship between the compressive strength and the elastic modulus of the concrete that had suffered combined deterioration is, as described above, thought to be close to that of Series TH, which has an elastic modulus smaller than that of Series HT, because fatigue and freezethaw damage act on the concrete alternately or simultaneously. The compressive strength of Series $\mathrm{TH}$, in which fatigue was applied after freeze-thaw damage, was greater than the compressive strength of Series $T$, in which only freeze-thaw damage was applied. The reason for this was the strain hardening phenomenon from cyclic loading. The details will be discussed in Section 3.2.1. When estimating the safeside compressive strength from the elastic modulus by using the relationship between the compressive strength and the elastic modulus shown in Figure 3 , it is considered to be desirable to eliminate the influence of strain hardening phenomenon, which increases the strength, and to instead use a single estimation equation for freeze-thaw deterioration only. The compressive strength of concrete that suffered freeze-thaw deterioration only is small.

\subsection{Influence of combined deterioration from fatigue and freeze-thaw damage on the mechanical properties of concrete}

To examine the transitions in the mechanical properties of concrete under freeze-thaw action and repeated loading, the transition in ultrasonic velocity (Figure 4), transition in compressive strength (Figure 5) and transition in elastic modulus (Figure 6) were obtained by using the data shown in Figures 1 and 2. 


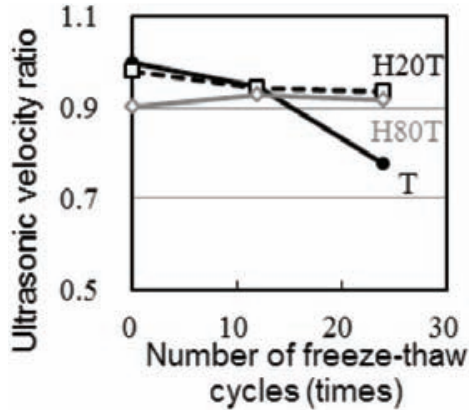

(a) Series T and HT

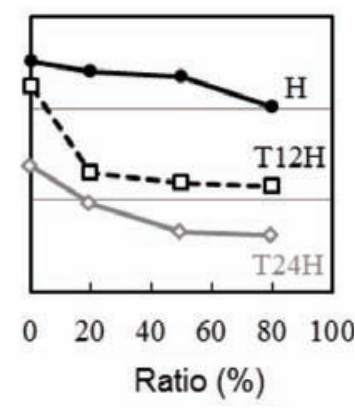

(b) Series $\mathrm{H}$ and $\mathrm{TH}$

Figure 4. Transition in ultrasonic velocity.

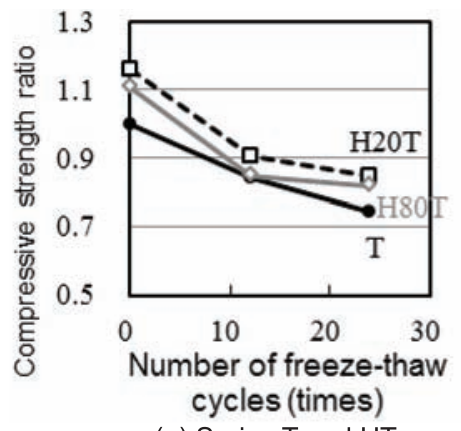

(a) Series $\mathrm{T}$ and $\mathrm{HT}$

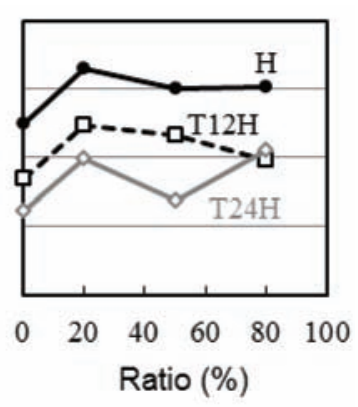

(b) Series $\mathrm{H}$ and $\mathrm{TH}$

Figure 5. Transition in compressive strength.

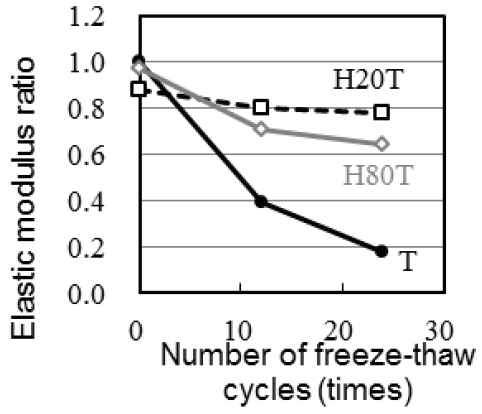

(a) Series $\mathrm{T}$ and $\mathrm{HT}$

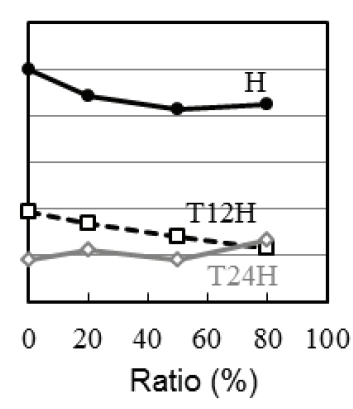

(b) Series $\mathrm{H}$ and $\mathrm{TH}$

Figure 6. Transition in elastic modulus.

To examine the influence of fatigue on the progress of freeze-thaw damage, (a) of each figure was created to show the results for Series T and Series HT. H20T means that the data are for Series HT, and the ratio is $20 \%$, and $\mathrm{H} 80 \mathrm{~T}$ means that the data are for Series HT, and the ratio is $80 \%$. To show the influence of freezethaw damage on the progress of fatigue, the results of Series $\mathrm{H}$ and $\mathrm{TH}$ are given in (b) of each figure. $\mathrm{T} 12 \mathrm{H}$ is for Series TH, and the number of freeze-thaw cycles is 12 times. $\mathrm{T} 24 \mathrm{H}$ is for Series $\mathrm{TH}$, and the number of freeze-thaw cycles is 24 times. The values on each plotted line are the average values of the values for three specimens with an equal deterioration level as shown in Table 2.

3.2.1 Transitions in mechanical properties

3.2.1.1 Ultrasonic velocity

In Figure 4(a), the ultrasonic velocity of Series $T$ is seen to greatly decrease with increase in the number of freeze-thaw cycles. The rate of decrease in ultrasonic velocity with increase in the number of freeze-thaw cycles for Series HT is small compared with that of Series T. When the ultrasonic velocity for Series HT and $T$ are compared for the same number of freezethaw cycles, the ultrasonic velocity for Series HT and that for Series $T$ are found to be roughly the same for 12 cycles; however, the ultrasonic velocity for Series $\mathrm{HT}$ is higher than that for Series $\mathrm{T}$ for 24 cycles. When H80T and H20T are compared, the ultrasonic velocity for $\mathrm{H} 80 \mathrm{~T}$ is smaller than that for $\mathrm{H} 2 \mathrm{OT}$ for all numbers of freeze-thaw cycles; however, the difference between them is small.

In Figure 4(b), the ultrasonic velocity for Series $\mathrm{H}$ decreases with increase in the ratio. For Series $\mathrm{TH}$, the ultrasonic velocity greatly decreases with increase in the ratio up to $20 \%$ for $\mathrm{T} 12 \mathrm{H}$ and up to $50 \%$ for $\mathrm{T} 24 \mathrm{H}$. The decreases in the ultrasonic velocity after the ratio of $20 \%$ for $\mathrm{T} 12 \mathrm{H}$ and $50 \%$ for $\mathrm{T} 24 \mathrm{H}$ are very small. When the ultrasonic velocity is compared for each ratio, Series $\mathrm{H}$ was found to have the greatest ultrasonic velocity decrease, followed by Series $\mathrm{T} 12 \mathrm{H}$ and then Series $\mathrm{T} 24 \mathrm{H}$.

\subsubsection{Compressive strength}

In Figure 5(a), the compressive strength decreases with increase in the number of freeze-thaw cycles for Series T. For Series HT, the compressive strength greatly decreases until the freeze-thaw cycles reach 12, after which the decrease becomes gentle. When compressive strength for Series HT and T are compared for the same numbers of freeze-thaw cycles, the values for Series HT are greater than, or roughly equal to, those for Series $\mathrm{T}$. When H80T and H2OT are compared in terms of compressive strength at each ratio, the compressive strength of H80T is found to be lower than that of H2OT at each ratio, as was true for ultrasonic velocity.

In Figure 5(b), the compressive strength for Series $\mathrm{H}$ at the ratio of $20 \%$ is higher than that at the ratio of $0 \%$, which is the compressive strength of a sound specimen, and it tends to become lower at ratios greater than 20\%; however, the values are higher than that of the sound specimen at each ratio. The reason the compressive strength is higher for Series $\mathrm{H}$ than for the sound specimen $\mathrm{N}$ is thought to be as follows. In the concrete that experienced loading below the fatigue limit in cyclic loading with uniaxial compression, a phenomenon similar to the strain hardening of metal occurs. The static strength of such concrete was reported to increase (Kishitani \& Nishizawa, 1987). It is thought that the compressive 
strength of Series $\mathrm{H}$ increased because of the same phenomenon. The compressive strength of $\mathrm{T} 12 \mathrm{H}$ at the ratio of $20 \%$ is higher than that at the ratio of $0 \%$ (specimen T12), as is true for Series $\mathrm{H}$, and it tends to decrease with increase in the ratio after that; however, the values are higher at each ratio than that at the ratio of $0 \%$. The compressive strength of $\mathrm{T} 24 \mathrm{H}$ at the ratio of $20 \%$ is higher than that at the ratio of $0 \%$ (specimen T24), which is similar to the results for Series $\mathrm{H}$ and $\mathrm{T} 12 \mathrm{H}$, and it shows a tendency of decrease at ratios greater than $20 \%$ until the ratio of $50 \%$.

However, the compressive strength at the ratio of $80 \%$ is higher than that at the ratio of $50 \%$. This difference may be a result of there only being one T24H80 specimen for these data. It was possible that the data from the only one specimen were higher than the average data of other specimens at the other ratios. The reason that data were taken for only one T24H80 specimen is that the other two specimens fractured during the cyclic loading before attaining $80 \%$ of the cycles of the fatigue life limit, because their strength had greatly decreased under freeze-thaw action before the loading test. When the values of compressive strength for Series $\mathrm{H}, \mathrm{T} 12 \mathrm{H}$, and $\mathrm{T} 24 \mathrm{H}$ are compared for a given ratio, Series $\mathrm{H}$ is found to have the greatest compressive strength, followed by $\mathrm{T} 12 \mathrm{H}$, and then $\mathrm{T} 24 \mathrm{H}$, as was the case for ultrasonic velocity.

\subsubsection{Elastic modulus}

In Figure 6(a), the elastic modulus of Series T greatly decreases with increase in the number of freeze-thaw cycles. The decrease in the elastic modulus for Series HT is smaller than that for Series T. When the elastic moduli of the two series at the same number of freeze-thaw cycles are compared, Series HT is higher than Series $T$ at each number of freeze-thaw cycles. When H80T and H2OT are compared in terms of compressive strength at each ratio, the compressive strength of $\mathrm{H} 80 \mathrm{~T}$ is found to be lower than that of H2OT at each ratio, as was true for ultrasonic velocity. The data point for 0 freeze-thaw cycles (no frost damage) does not fall into the above categorization. The details are discussed in the explanation on Series $\mathrm{H}$ in Figure 6(b).

In Figure 6(b), the elastic modulus of Series $\mathrm{H}$ decreases with increase in the ratio until the ratio of $50 \%$; however, it flattens out from the ratio of $50 \%$. The elastic modulus of $\mathrm{T} 12 \mathrm{H}$ decreases very gently with increase in the ratio. It is possible for the elastic modulus of $\mathrm{T} 24 \mathrm{H}$ at the ratio of $80 \%$ to be greater than the average value, as is true for compressive strength. The value begins to increase at the ratio of $50 \%$, but the values at other ratios do not increase or decrease very much. When the elastic moduli for Series $\mathrm{H}, \mathrm{T} 12 \mathrm{H}$, and $\mathrm{T} 23 \mathrm{H}$ are compared for a given ratio, Series $\mathrm{H}$ is found to have the greatest value, followed by $\mathrm{T} 12 \mathrm{H}$ and then $\mathrm{T} 24 \mathrm{H}$, as was the case for ultrasonic velocity.

\subsubsection{The influence of fatigue on the progress of frost damage}

As discussed above, the ultrasonic velocity and elastic modulus did not decrease very much, even though the compressive strength decreased with increase in the number of freeze-thaw cycles, as was the case for Series $T$. The reason for the above is thought to be the following.

Figure 7 shows the transition of strain in concrete for Series T and HT at the end of each freeze-thaw cycle up until six cycles. From this figure, it is found that Series $T$ shows increasing expansion with increase in the number of freeze-thaw cycles; however, Series HT does not show such expansion. H20T does not expand, and it even shrinks from the end of the sixth cycle. To examine this phenomenon in detail, the relationship between temperature and strain during the sixth freeze-thaw cycle shown in Figure 8 was examined. Series $T$ greatly expands in the region of sub-zero temperatures and has residual strain in the direction of expansion from the end of the freezethaw cycles.

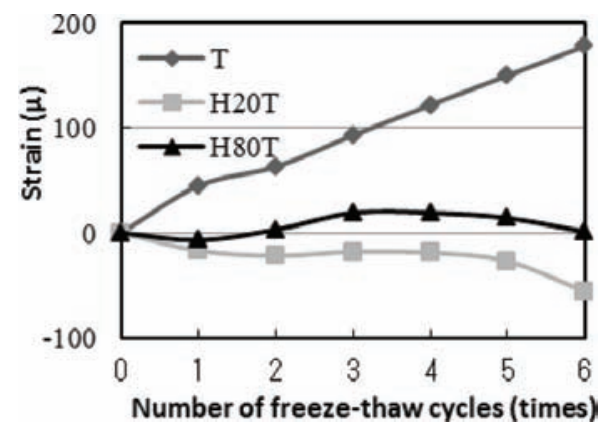

Figure 7. Transition of strain at the end of each cycle.

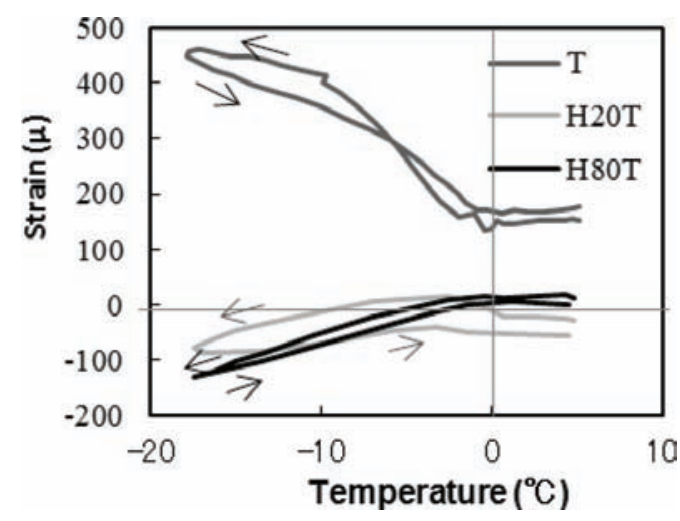

Figure 8. Temperature vs. strain (at the sixth cycle). 
Series HT shrinks in the region of sub-zero temperatures, and residual strain in the direction of shrinkage is found from the end of the freeze-thaw cycles. H80T has greater maximum shrinkage than $\mathrm{H} 20 \mathrm{~T}$ does in the region of sub-zero temperatures. Shrinkage behaviour in the region of sub-zero temperatures is a phenomenon seen in $\mathrm{AE}$ concrete. The reason for $A E$ concrete showing shrinkage behaviour in the region of sub-zero temperatures is considered to be that the ice crystals, which formed in voids in the concrete absorb moisture from the concrete around them, and that the concrete shrinks according to how much water moves from the concrete toward the ice crystals (CERI, 2011). In light of the above, it is possible that for Series HT, the minute cracks caused by fatigue play the role that voids do in AE concrete.

The difference between the maximum strain and the residual strain after the end of cyclic loading was about $1000 \mu \mathrm{m}$ for H80T and about $900 \mu \mathrm{m}$ for H20T. The amplitude of shrinkage strain from freeze-thaw action at the 6th cycle was about $130 \mu \mathrm{m}$ for H80T and about $90 \mu$ for H20T. Both values are within the range of difference in the maximum strain at cyclic loading and the residual strain after cyclic loading. The deformation from freeze-thaw action was within the range of deformation that occurred from the cyclic loading done before the freeze-thaw test, and the difference between the maximum strain and the residual strain after cyclic loading was about $10 \%$, which is small. In light of the above, it can be thought that the influence of external force caused by the freeze-thaw action was small.

In Series HT, the width and density of minute cracks formed from fatigue did not progress much, even with freeze-thaw action. Therefore, the ultrasonic velocity and elastic modulus, which are thought to be influenced greatly by minute cracks, did not decrease very much with freeze-thaw action.

\subsubsection{The influence of frost damage on the progress of fatigue}

As discussed above, the decrease in the compressive strength and elastic modulus for Series TH from fatigue was small, because these had already greatly decreased when the specimens were subjected to frost damage. The decrease in ultrasonic velocity for Series TH was also small after it decreased greatly at the low ratio of $20 \%$, even when the ratio increased. In Series $\mathrm{TH}$, the influence of deterioration from frost damage on the mechanical properties of the specimens was great, but the influence of fatigue on the specimen was smaller than that of frost damage.

When frost damage was applied before fatigue, the frost damage had a very great influence on the fatigue resistance (fatigue life) of the specimen. Figure 9 shows the fatigue life (logarithmic value) for every relative dynamic modulus of elasticity; it indicates the degree of deterioration from the preceding frost damage.

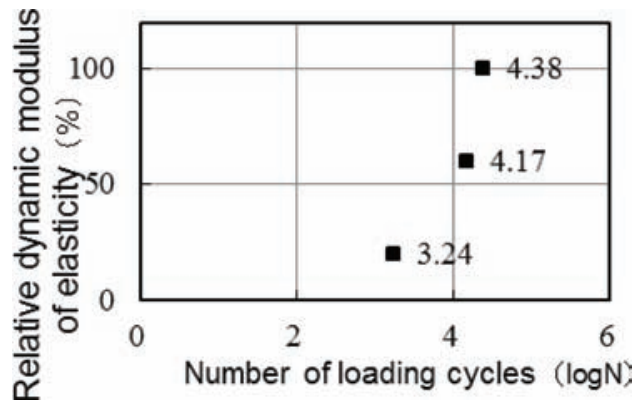

Figure 9. Relative dynamic modulus of elasticity vs. fatigue life.

The fatigue life $(\log N)$ at the $60 \%$ relative dynamic modulus of elasticity (after 12 freeze-thaw cycles) is 4.17. The fatigue life of the specimen after 12 freezethaw cycles is only slightly smaller than the fatigue life of 4.38 for the sound specimen with $100 \%$ relative dynamic modulus of elasticity. The fatigue life of the specimen with $60 \%$ relative dynamic modulus of elasticity (after 24 freeze-thaw cycles) shows the very small value of 3.24 .

The following are possible reasons for the decrease in fatigue resistance caused by the preceding frost damage. Fatigue failure is a phenomenon in which cracks that form inside concrete gradually progress and propagate under cyclic stress until ultimate failure (Kishitani \& Nishizawa, 1987). However, the concrete that suffered preceding frost damage has minute cracks from the freeze-thaw action that occurred before the cyclic stress. The greater the deterioration from frost damage (i.e., the smaller is the relative dynamic modulus of elasticity), the higher the density of minute cracks. Therefore, when the concrete that suffered frost damage experiences cyclic stress, cracks rapidly propagate through the existing minute cracks from frost damage, which shortens the fatigue life of the concrete.

\section{CONCLUSION}

Using cylindrical specimens whose variables were the order and degree of deterioration, a method for evaluating the mechanical properties of concrete that had undergone combined deterioration from fatigue and frost damage was examined. The influence of combined deterioration on the mechanical properties of concrete was evaluated by using ultrasonic propagation velocity. The following were found.

(1) In evaluating the mechanical properties of concrete that has suffered combined deterioration from fatigue and frost damage, it is possible to 
estimate the elastic modulus from the ultrasonic velocity by using the relatively high correlation between ultrasonic velocity and elastic modulus. It is possible to estimate compressive strength by using the relationship between compressive strength and elastic modulus; however, because of strain hardening, the compressive strength of concrete that has suffered combined deterioration is greater than that of concrete that has undergone deteriorated only from frost damage. Therefore, to estimate a safe-side compressive strength, it is desirable to use an estimation equation for deterioration from frost damage only, which has smaller values than that for combined deterioration.

(2) The compressive strength of concrete that has suffered combined deterioration from fatigue followed by frost damage was found to decrease with increase in the number of freeze-thaw cycles, as is true for the concrete that suffered from frost damage only; however, the ultrasonic velocity and the elastic modulus were not found to decrease noticeably. For the reasons above, it is thought that the minute cracks which formed from fatigue may act as voids in AE concrete, and that the amplitude of the shrinkage strain by freezethaw action is within the range of the difference between the maximum strain at loading and the residual strain at completion of loading.

(3) In concrete that has suffered combined deterioration from frost damage followed by fatigue, the decrease from fatigue is small, because the compressive strength and the elastic modulus had already greatly decreased before the specimen was subjected to frost damage. The ultrasonic velocity decreased up until a low ratio, and the decrease was small even with increase in the ratio. Preceding frost damage was found to have a very great influence on the fatigue life of the specimen. The reason for the great influence of frost damage on the fatigue life of concrete is thought to be that when concrete that has already experienced frost damage receives cyclic stress, minute cracks that have formed from frost damage rapidly propagate and shorten the fatigue life of the concrete.

Toward establishing an evaluation method for mechanical properties of concrete that has suffered combined deterioration from fatigue and frost damage, we will conduct further examinations on cases of combined deterioration in which fatigue and freeze-thaw damage are alternately given, and on the application of the developed evaluation technique to actual structures.

\section{REFERENCES}

CERI. (2011). Study on durable concrete designs against combined deterioration from freeze-thaw and chloride and improvement of durability using barrier penetrants. Report of the Civil Engineering Research Institute for Cold Region, 133.

Hayashida H., Taguchi F., Endo H., \& Kusama S. (2008). A basic study on frost damage diagnosis for concrete structures using the measurement of ultrasonic propagation velocity. Monthly Report of the Civil Engineering Research Institute for Cold Region (No. 656), 1, 10-15.

Japan Society of Civil Engineering. (2012). "Design" of standard specifications for concrete structures.

Kishitani, K. \& Nishizawa, N. (1987). Series on the durability of concrete structures: fatigue. Gihodo Shuppan.

Mitamura, H., Sato, T., Honda, K., \& Matsui, S. (2009). Frost damage deterioration to the upper surface of the RC deck of a highway bridge, and the influence of that deterioration on the fatigue life of the bridge. Journal of Structural Engineering, 55A, 1420-1431.

Takashiba, Y., Sakai, K., \& Kumagai, M. (1998). Mechanical properties of concrete that has suffered deterioration from frost damage and alkali-aggregate reaction. Proceedings of the Japan Concrete Institute, 20(1), 221-226. 